\title{
Armas de fuego e (in)seguridad en América Central en el siglo XXI
}

\author{
Anuario Latinoamericano \\ Ciencias Políticas \\ y Relaciones Internacionales \\ vol. 7, 2019 \\ pp. 313-328
}

\section{Firearms and (In)security in Central America in the $21^{\text {st }}$ Century}

DOI: 10.17951/al.2019.7.313-328

\author{
Michat Stelmach* \\ FACULTAD DE ESTUDIOS INTERNACIONALES Y POLÍTICOS \\ UNIVERSIDAD DE ŁÓDŹ, POLONIA \\ $\triangle$ michal.stelmach@uni.lodz.pl \\ https://orcid.org/0000-0001-5857-6262
}

\section{RESUMEN}

América Central enfrenta actualmente muchos desafíos, y uno de los mayores es la violencia criminal y los asesinatos llevados a cabo con armas de fuego, que representan hasta el 70\% de todos los homicidios. El objetivo del artículo es analizar las condiciones y los mecanismos del comercio ilegal de armas y la correlación entre la disponibilidad de armas y el nivel de crimen y violencia en América Central en el siglo XXI.

PALABRAS CLAVE: tráfico ilícito, armas de fuego, violencia criminal, inseguridad, América Central.

\begin{abstract}
Central America currently faces many challenges, and one of the biggest ones is criminal violence and murders carried out with firearms, which represent up to $70 \%$ of all homicides. The objective of the article is to analyze the conditions and mechanisms of illegal arms trade and the correlation between the availability of weapons and the level of crime and violence in Central America in the $21^{\text {st }}$ century.
\end{abstract}

KEYWORDS: illicit trade, firearms, criminal violence, insecurity, Central America.

* Politólogo, latinoamericanista. Doctor en Ciencias Políticas por la Facultad de Estudios Internacionales y Políticos de la Universidad de Łódź, Polonia. Coeditor de dos monografías: Política exterior de Polonia. 25 años de experiencia y Investigar la política exterior del Estado. Estados Unidos, Asia Oriental, Medio Oriente y América Latina. Secretario general de la Sociedad Polaca de Estudios Latinoamericanos y miembro de la Sociedad Polaca de Estudios Internacionales. 


\section{Introducción}

América Central enfrenta actualmente muchos desafíos, y uno de los mayores es la violencia criminal y los asesinatos llevados a cabo con armas de fuego, que representan la gran mayoría de todos los homicidios. El objetivo de este artículo es analizar las condiciones y los mecanismos del mercado ilegal de armas y la correlación entre la difusión y la disponibilidad de armas y el nivel de violencia en los países centroamericanos en el siglo XXI. Formulo la tesis que el uso más frecuente de armas para cometer actos delictivos, incluidos homicidios, en América Central que en otras regiones de América Latina, resulta no solo y no principalmente de la difusión y el fácil acceso de los ciudadanos a las armas, sino que está, sobre todo, condicionado por el contexto sociopolítico, así como factor cultural -la tradición de la violencia, que es profundamente arraigada y se manifiesta en muchos niveles de las relaciones sociales, incluida la relación entre el Estado y los ciudadanos.

El artículo consta de 4 secciones. En la primera, describo el estado de inseguridad en América Central. Muestro el alcance de la criminalización en los países de la región, presentando datos sobre el número de homicidios en países de la región y prestando atención al alto porcentaje de asesinatos cometidos con el uso de armas de fuego. En la segunda sección, caracterizo el mercado negro de armas de fuego en América Central. Identifico las fuentes de armas y analizo los mecanismos que permiten introducir armas al comercio ilícito. La tercera parte está dedicada al contrabando ilegal de armas. Basándome en la literatura disponible, señalo las rutas y métodos de tráfico ilegal de armas de fuego. En la cuarta sección del artículo, identifico y analizo los factores que favorecen el tráfico ilegal de armas y los altos niveles de violencia en América Central.

La reflexión tiene principalmente la naturaleza sistémico-funcional y comparativa. Los métodos que se utilizaron en el estudio -análisis de datos numéricos y observación de tendencias, análisis legal, estudios de casos en una perspectiva comparativa- permiten identificar los determinantes y la especificidad de la violencia en Centroamérica.

\section{Violencia criminal en América Central}

En el actual período de paz y democracia, la violencia criminal se ha convertido en el mayor desafío para los países de América Central. Al analizar este fenómeno, pueden destacarse varios rasgos peculiares. En primer lugar, la "nueva violencia" en este tiempo de paz es de carácter civil, y las principales víctimas son los ciudadanos (Koonings y Kruijt 2004: 8-10). En segundo lugar, se trata de una consecuencia directa de la actividad del crimen organizado -cárteles de narcóticos, bandas, pandillas y maras, así como de un elemento fijo de los conflictos por la tierra y de los enfrentamientos interpersonales (La- 
gos, Dammert 2012; OEA 2012, PNUD 2013) y de las estrategias radicales para la seguridad pública implementadas por los países de la región.

En tercer lugar, la intensidad de la violencia en la región de América Central es diversa. Los países de América Central se pueden dividir según su nivel de violencia en tres grupos: países con índices de homicidio alto, medio y bajo. El primero abarcaría el llamado Triángulo Norte: El Salvador - 51/100 mil habitantes, Honduras - 40/100 mil habitantes y Guatemala 22/100 mil habitantes y Belice - 35,9/100 mil habitantes (Dalby, Carranza 2019). Esas cifras son considerablemente altas para los estándares globales, pero constituyen una caída notable respecto a la tasa de 2016 (excepto Belice). Más aún, un pequeño porcentaje de ciudadanos cree que el crimen se redujo en 2017, según una encuesta reciente. El gran número de homicidios de estos tres países suele asociarse principalmente con la actividad y la rivalidad de dos bandas, MS y la Calle 18, y el desarrollo vertiginoso del crimen organizado, incluyendo la presencia cada vez mayor de los cárteles mexicanos de la droga. El segundo grupo incluiría los dos llamados países del Triángulo Sur: Costa Rica (603 homicidios) - 11,7/100 mil habitantes (el mayor número en la historia del país) y Panamá - 9,6/100 mil habitantes, donde el número de homicidios en los últimos años ha aumentado significativamente. La gran parte de los asesinatos en Costa Rica están relacionados con el crimen organizado, especialmente con el narcotráfico (25\%), así como con la actividad de pandillas locales (InSight Crime 2018). Es importante destacar que actualmente solo Nicaragua está por debajo del umbral de la epidemia de delitos: 7/100 mil habitantes (datos de 2017), siendo el único Estado de la región que podría jactarse de estar entre los países con menor número de homicidios (Dalby, Carranza 2019).

En cuarto lugar, la mayoría de los homicidios en América Central se perpetran con armas de fuego: el 69\% en el período comprendido entre 2007-2012. En Honduras, los homicidios con armas de fuego representan hasta el 96\% de los casos, en El Salvador y Guatemala más del $80 \%$ y en Costa Rica y Panamá alrededor del $70 \%$. Mientras que a escala mundial solo un tercio de los feminicidios se comete con armas de fuego, en Honduras y Guatemala, hasta un 60\% de los asesinatos de mujeres se producen por herida de bala (UNODC 2015: 28)

\section{Mercado ilegal de armas en América Central}

El tráfico ilícito de armas en América Central no afecta significativamente al desarrollo y la intensidad de los conflictos regionales. Las transacciones relacionadas con el mercado negro tienen un impacto decididamente mayor, incluso crucial, en el desarrollo del crimen y en el aumento del nivel de violencia en los diferentes países. El mercado negro de armas afecta principalmente al orden público y la seguridad dentro de cada país y, por lo general, no genera amenazas de índole internacional.
Armas de fuego

e (in)seguridad

en América Central en el siglo XXI

Michał Stelmach 
Debido a la naturaleza confidencial de todas las transacciones, resulta extremadamente difícil detectar los mecanismos en actuación dentro del mercado negro de armas, así como elaborar el catálogo de métodos y técnicas utilizadas por los traficantes de armas y contrabandistas. Sin embargo, resulta fácil de identificar la procedencia de las armas y las formas de introducirlas en el mercado ilícito de América Central.

En primer lugar, cabría señalar que la fuente inagotable de armas en América Latina son los depósitos de empresas de seguridad privada y policiales. En 2015 había más de 660,000 armas pequeñas en posesión de empresas de seguridad privada en 17 países de América Latina, de las cuales 90.500 armas de fuego están en posesión de empresas guatemaltecas, 30.000 - costarricenses, más de 20.000 - salvadoreñas y hondureñas, y más de 11.000 - nicaragüenses. En Belice, un Estado con las tasas muy altas de homicidios, las empresas privadas tienen una pequeña cantidad de armas - 260 armas de fuego (Godnick 2016: 20-21). El sector privado es el principal proveedor de armas para los grupos criminales en Guatemala, Honduras, El Salvador y en Costa Rica. Según las estimaciones, más del $40 \%$ de las armas ilegales en El Salvador provienen de más de 460 compañías que ofrecen servicios de seguridad. En Costa Rica las empresas "perdieron” más de 7.000 registradas hasta el 2013 (Bosworth, Kinosian 2018: 9). En 2015 fueron arrestadas por contrabandear armas ordenadas por Mara Salvatrucha 90 personas, incluidas 2 relacionadas con compañías de seguridad privadas. En Honduras los grupos criminales crean compañías de seguridad y tratan las como una fuente de armas (grupo de Valley).

La vía de introducción de armas en el mercado ilegal pasa también por la expropiación de los almacenes de la policía y el ejército, e igualmente por la venta de armas a grupos criminales a manos de los funcionarios mal remunerados de las fuerzas de seguridad y a manos de los agentes de empresas de seguridad privadas, quienes ven en el tráfico de armas y municiones un modo de aumentar sus bajos ingresos. Este es el caso que se da en todos los países de la región; además, las transferencias de armas procedentes de robos tienen lugar en muchas direcciones. Los períodos que registran un mayor riesgo de sustracción de armas son, por lo general, aquellos en los que se producen crisis graves y conflictos internos. Sin embargo, en América Central, el robo de armas y municiones también tiene lugar en condiciones de relativa estabilidad. En 2010, se descubrieron en Guatemala 43 armas cuyo origen eran los almacenes del ejército. A su vez, en marzo del 2011, las autoridades de El Salvador revelaron que, a lo largo de 24 meses, 1.731 armas de fuego registradas por las compañías de seguridad fueron a parar al mercado ilegal (Godnick, Bustamante 2013: 297).

La transferencia de armas de los almacenes se ve facilitada por la pésima seguridad imperante, pero, sobre todo, por la falta de regulaciones jurídicas adecuadas en los capítulos referentes al armamento y a los equipos utilizados por los funcionarios, en el caso de los grandes excedentes de armas que se produjeron cuando se dio la radical y repentina reducción del número de 
personal militar durante la transición política, que no fue acompañada de una reducción proporcional del armamento. Actualmente, los miembros de las fuerzas de seguridad en los países de América Central disfrutan, en principio, de un acceso ilimitado a las armas. En la práctica, los supervisores no tienen ningún conocimiento sobre el número de armas suministradas a los agentes de modo individual, lo que crea un espacio ideal para el abuso. La introducción de restricciones sobre el acceso a las armas y el establecimiento de un mecanismo de control efectivo y una contabilidad estricta de las piezas en posesión y de la munición utilizadas por cada soldado contribuiría, probablemente, a reducir el número de casos no resueltos de "extravío de armas", que hoy en día siguen gozando de una falta general de consecuencias disciplinarias y, por supuesto, penales.

En segundo lugar, deben ser mencionado los restos armamentísticos de las guerras civiles. Tras el fin de las guerras civiles (Guatemala, El Salvador, Nicaragua) y a pesar del proceso de desmilitarización, todavía circulan por la región clandestinamente muchos miles de armas. Se estima que, en El Salvador, su número ascendería a unas 360.000 armas de tipo militar. Se supone que la mayoría ha sido transferida a países vecinos. Tenemos una situación similar en Guatemala, donde solo se devolvieron menos de 2.000 armas después del final del conflicto. En Nicaragua, el proceso de desmovilización cubrió a 91.000 personas y lo que es interesante, solo 17.000 armas de fuego fueron entregadas a los depósitos del Estado. Según diversas fuentes, millones de fusiles circulan en el mercado negro, fuera de control (UNODC 2012: 60). Lo que parece más inquietante es que las armas confiscadas a los ciudadanos, como parte de las acciones a escala nacional, retornan a menudo al mercado negro, ya que son sustraídas o llevadas por los mismos funcionarios, volviendo a ser sujeto de comercio ilegal. Sin embargo, debe recordarse que los fusiles constituyen solo un pequeño porcentaje de las armas requisadas por la policía con motivo de la detención de delincuentes. Las armas largas rara vez se usan cuando se cometen delitos comunes. Por ejemplo, en Guatemala, entre el 2008 y el 2011, se incautaron entre 4 y 5 mil armas, de las cuales hasta un $60 \%$ eran pistolas. Los fusiles de asalto representaron solo el $4 \%$ de las armas confiscadas. Las armas más habituales fueron las armas de $9 \mathrm{~mm}(61 \%$ de las armas confiscadas). La situación es semejante en Honduras, donde el 63\% de las armas adquiridas son pistolas de $9 \mathrm{~mm}$ (adquiridas entre 2008-2011). Los revólveres son más populares en Honduras que en Guatemala, en cambio los fusiles de asalto son igual de poco frecuentes (4\%) (UNODC 2012: 60-61). Por lo tanto, aunque el armamento militar ha quedado como una herencia de las guerras civiles no constituye la mayor preocupación, puesto que el mercado local de armas no se basa, en realidad, en esta clase de almacenamientos.

Las colecciones privadas también son una fuente importante de armas. En América Central, el acopio de armas por parte de civiles supera al de los militares y la policía. Según estimaciones, alrededor de 2.200.000 armas están registradas en América Central, de las cuales 870.000 pertenecen a las fuerzas
Armas de fuego e (in)seguridad en América Central en el siglo XXI

Michał Stelmach 
de seguridad y 1.400 .000 a particulares. Además, las armas no registradas, que se estima que ascienden a 2.800.000, también deberían incluirse (UNODC 2015: 59). Tal cantidad de armas en el mercado permitiría armar a cada uno de tres hombres en la región. Sin embargo, se debe recordar que cientos e incluso miles de armas son armas de coleccionista. Sin embargo, suele suceder que un arma legalmente adquirida y oficialmente registrada se pierde o le es robada al propietario y, en consecuencia, se convierte en objeto de comercio ilegal. Vale la pena señalar que, en los países de América Central, la compra de armas en la tienda generalmente se registra. El problema surge cuando el primer dueño vuelve a vender el arma a otra persona. Las transacciones de este tipo rara vez se registran, por no decir que no se registran nunca.

Otra forma muy extendida de introducir armas legalmente adquiridas en el mercado negro es la de utilizar las "lagunas" en las regulaciones legales y la incongruencia en las regulaciones legales de los Estados de la región en el ámbito de la compra, tenencia y transporte de armas. En países con regulaciones liberales sobre el acceso a armas de fuego, el fenómeno conocido como "compra de paja" es común. Este procedimiento estriba en la compra de armas por segundas personas, "no fichadas", es decir, sin antecedentes penales (llamadas columnas), y luego revenderlas a personas que, debido a conflictos con la ley o por incumplimiento de los requisitos legales, no pueden permitirse el adquirir armas en una tienda autorizada para ello. Este fenómeno es muy común en los Estados Unidos. Se pueden comprar una gran cantidad de armas con licencia en las ferias de armas (gun shows), por ejemplo, en Texas. En la frontera el comprador entra en contacto con el traficante de armas, el cual las transfiere a los grupos criminales interesados en México (Lucatello 2012: 52-53).

Además de la gran popularidad de las ferias de armas, donde se puede comprar, sobre todo, armas de tiro, son las tiendas libres de impuestos (Duty Free) las que gozan de gran interés, principalmente en los Estados Unidos y en América Central, en Panamá. Este último país, debido al sistema de compras en esa clase de tiendas, desempeña un papel especial en el comercio regional de armas. La venta abierta de armas y municiones también tiene lugar en la zona fronteriza de San Cristóbal y Ocotepeque, entre Honduras y Guatemala (Lucatello 2012: 53, Rosa de León-Escribano 2011: 82).

En el mercado negro circulan igualmente armas caseras conocidas como armas hechizas en el mercado negro. Son utilizadas, sobre todo, por miembros de pandillas callejeras y pequeños delincuentes que por alguna razón (suministro limitado o restricciones introducidas por el Estado) no pueden llevar armas o no pueden pagarlas (aunque las armas son relativamente baratas, ya que es posible comprar un rifle AK 47 por 200-400 dólares). En América Central, los miembros de pandillas juveniles montan armas de fuego con armazones de las camas y tuberías de metal. En El Salvador, en Santa Ana, los talleres que operan ilegalmente producen imitaciones de pistolas calibre 0.22 y 0.38 mm (Stohl 2006: 55-61). Es importante destacar que este tipo de armas se fabrican para el uso personal y no se exportan. 


\section{Tráfico ilícito de armas de fuego en América Central}

En Mesoamérica, los mayores receptores de armas son los grupos delictivos organizados, que operan principalmente en México, y cada vez más los cárteles de la droga centroamericanos, así como las organizaciones delictivas involucradas en la trata y el tráfico de personas, el robo de automóviles y el contrabando de minerales. Su actividad criminal exige la posesión de varios tipos de armas que sean fáciles de transportar y que, al mismo tiempo, resulten sumamente eficaces. El segundo grupo de receptores está formado por los grupos criminales transnacionales, las maras y las bandas locales, las pandillas, que operan en los centros de las grandes ciudades centroamericanas. El tercer grupo se halla constituido por unidades paramilitares: grupos de autodefensa, escuadrones de la muerte y compañías de seguridad (Rosa de León-Escribano 2011: 80-81). Un grupo sorprendentemente grande es el de los clientes individuales. Se observa una elevada demanda de armas en lugares donde la cultura de la violencia es todavía fuerte y el control sobre su tenencia y porte es débil (por ejemplo, cerca de la frontera entre El Salvador y Honduras). Es fácil abastecerse en los mercados locales, y la sensación de impunidad alienta a las personas a poseerlas de manera ilegal y a tomarse la justicia "por su mano". En las últimas décadas, hemos visto cambios significativos entre los receptores de armas. Si bien en el pasado el principal receptor de armas ilegales eran las fuerzas irregulares, es decir grupos partisanos y unidades paramilitares, hoy en día son los cárteles de la droga, los grupos delictivos transnacionales, las bandas locales y los pequeños delincuentes.

En las últimas dos décadas, la corriente y las direcciones de armas y municiones han experimentado transformaciones significativas. El flujo bidireccional consistente en transferencia de armas al sur y de drogas al norte han sido reemplazadas por conexiones más complicadas y multidireccionales. Ante todo, debe distinguirse el comercio de armas entre los países de América Central y el comercio de armas fuera de la región, es decir, el tráfico de armas hacia México y Colombia. En función de los datos disponibles, se puede intentar esbozar los mercados y las rutas más actuales del tráfico de armas.

1. Las rutas centroamericanas: los principales centros de distribución son Honduras y Nicaragua y los receptores, los grupos delictivos de Guatemala y El Salvador. Después de cruzar la frontera de El Salvador, el arma es transportada a la capital, San Salvador, donde se vende a un precio que oscila entre los 100 y los 150 dólares. Las escopetas y los lanzagranadas van a Guatemala; la ruta norte-sur, en la cual la mercancía se compra en los Estados Unidos, transportándose primero a México, luego a Guatemala y finalmente a El Salvador y Honduras.

2. La ruta sur-norte: las armas se transportan desde los países centroamericanos hacia el norte y, a través del departamento de Peten (Guatemala), llegan a México, donde son recibidas por los cárteles de la droga. Según datos estimados, más de la mitad de las armas de tipo militar confiscadas
Armas de fuego e (in)seguridad en América Central en el siglo XXI

Michał Stelmach 
por las autoridades mexicanas provienen de América Central. Las granadas y las ametralladoras provienen principalmente de los almacenes militares guatemaltecos. En 2009, se incautaron cantidades significativas de armas y municiones originarias de Guatemala en Chiapas. Las armas pesadas provienen principalmente de Honduras y, curiosamente, fueron vendidas en el pasado a Honduras por los Estados Unidos. Los investigadores indican que la costa del Pacífico guatemalteco (especialmente la provincia de San Marcos) juega un papel importante en la transferencia de armas ilegales de Panamá a México (UNODC 2012: 643. La ruta colombiana. Las investigaciones de UNODC señalan que el 36\% de las armas de fuego ilegales de contrabando que llegan a Colombia provienen de Centroamérica, especialmente de Nicaragua y Panamá (UNODC 2012: 61). El mayor exportador de armas ilegales a Colombia es Nicaragua. La policía y el ejército nicaragüense localizaron siete puntos "calientes" en el contrabando de armas. Los tres primeros se sitúan en la frontera con Honduras: El Guasaule, Las Manos, El Espino y Teotecacinte, y otros cuatro en la frontera costarricense: Peñas, Blancas, San Carlos y El Castillo. Lo raro del caso es que estos son puntos fronterizos oficiales, donde los servicios de aduana están presentes y en los cuales, al menos en teoría, debería ser más fácil combatir el contrabando. Aparte de los mencionados, existen otros lugares a lo largo de toda la frontera sobre los cuales las autoridades no tienen control (REDCEPAZ 2006: 12-13). Por su parte, Panamá sería un centro comercial importante debido a su ubicación y a la proximidad con Colombia, pero principalmente debido a su legislación bancaria liberal y a la posibilidad de comprar armas en tiendas libres de impuestos. Además, cabe destacar que los ciudadanos panameños a menudo se ven forzados a llevar armas en sus barcos o poner sus barcos a disposición de los contrabandistas profesionales. La frontera entre Costa Rica y Nicaragua también ocupa un lugar significativo en el contrabando de armas a Colombia. El arma es transportada a Colombia por la costa atlántica y a través del río San Juan. En el caso de la frontera con Honduras, son Waspam y Sandy Bay los principales centros de tráfico y en la frontera con Costa Rica son Cárdenas (Rivas), Boca de Sábalos, Boca Tapada y el río San Juan. En la zona de Waspam y del Río San Juan, los grupos delictivos formados principalmente por exguerrilleros y miembros de los cárteles de la droga, que operan en la región habitada por los indios Misquitos, intercambian armas por narcóticos con las células responsables del tráfico de drogas en la ruta San Juan - San Carlos Chontales - Managua. En el tráfico de armas a Colombia, los habitantes de la provincia costarricense de Liberia también están involucrados (algunas de las armas se quedan en Costa Rica y se venden en el mercado negro). En Costa Rica, las armas se contrabandean principalmente desde Nicaragua, pero también desde Panamá (en pequeñas cantidades, porque la mayoría de las armas largas se dirigen hacia el sur, hacia Colombia) (REDCEPAZ 2006: 20-22). 


\section{Catalizadores del comercio ilegal de armas y violencia}

Aquí debería abordarse la cuestión de la correlación entre el acceso a las armas y el nivel de violencia. Podría suponerse que un índice tan elevado de asesinatos con el uso de armas es una consecuencia del fácil acceso a las armas pequeñas y ligeras. Se estima que en América Latina su número llega aproximadamente a 63 millones de piezas, de las cuales el 85\% (53 millones) está en las manos de civiles, casi el 9\% (5,5 millones) en las de las fuerzas armadas, el 4\% (2,6 millones) en las de la policía y el 2\% (1,2 millones) en las de las fuerzas paramilitares. Sin embargo, resulta que los países con altas tasas de posesión legal de armas se caracterizan por tasas de homicidios mucho más pequeñas (por ejemplo, Uruguay) que los países centroamericanos. En países con altas tasas de homicidios, El Salvador y Honduras, en manos de civiles, según las estadísticas oficiales, hay muchas menos armas (6,2 armas por cada 100 habitantes). Entonces, ¿qué determina el alto nivel de violencia criminal en América Central? La violencia criminal, extremadamente intensificada en América Central, debe considerarse en un contexto sociopolítico más amplio y sus causas examinadas según las condiciones en las que funciona cada país.

Cabe señalar factores que constituyen una especie de catalizador del comercio ilegal de armas y de los altos niveles de violencia con uso de armas de fuego en América Central.

\section{Desarrollo de la delincuencia organizada transnacional en la región}

El desarrollo de diversas formas de delincuencia organizada en la región podría considerarse como el factor externo más importante, directamente determinante en relación con las dimensiones y la intensidad de la circulación ilegal de armas en América Central y generador al mismo tiempo de violencia. El narcotráfico, a su vez, sería el mayor sector del crimen organizado en la región. Desde el punto de vista de los grupos criminales, Centroamérica siempre ha sido un puente natural entre los principales productores de drogas (Colombia y México) y los mercados (EE. UU. y Europa). En América Central, el tráfico de drogas no es un fenómeno nuevo, pero en los últimos años, debido a varios factores, ha cobrado una dinámica completamente nueva. En un período de tiempo relativamente breve, los países centroamericanos se han convertido en un área de especial interés, a lo que ha seguido de inmediato una mayor actividad de los cárteles de la droga, sobre todo mexicanos. Existe un claro vínculo entre la agudización de la estrategia en la lucha antidroga en México después de 2006 y el aumento de los cárteles en los territorios de América Central. En la última década hemos asistido a un fenómeno que puede ser definido como el "efecto cucaracha", esto es, la dispersión de los grupos delictivos organizados, que desde los países y las regiones cubiertas por los programas radicales para combatir el crimen organizado (México y Colombia),
Armas de fuego e (in)seguridad en América Central en el siglo XXI

Michał Stelmach 
se han desplazado a los Estados débiles. De esta manera, los éxitos de un país en la lucha contra el crimen se convierten en una fuente de problemas para los países vecinos. La ilustración de este fenómeno es, sin duda, el interés de los cárteles del Golfo, los Zetas y Sinaloa, por Guatemala y Honduras. Los narcotraficantes, aprovechándose de la trágica situación económica y de la lasitud de las instituciones del Estado en estos países, han tomado con toda tranquilidad el control de áreas sustanciales de estos países, donde se ven libres para realizar sus negocios con el apoyo de grupos criminales locales (Los Perrones en El Salvador, la familia tradicional de los Mendoza y los Lorenzo, así como el nuevo grupo de Los Zarceños, Los Ponces y la red Chamale en Guatemala) (UNODC 2012: 20-27). Según los datos estimados, el 88\% de los narcóticos que llegan a México y Estados Unidos pasan por la región centroamericana. La mayoría de las drogas llegan a Honduras desde América del Sur por vía marítima (los puertos de la costa atlántica) o por aire (departamento de Olancho), y luego son transportadas a través de la zona noroeste o por los caminos que transcurren a lo largo de la costa del Pacífico, desde El Salvador a Guatemala, o que conducen directamente a Guatemala. En Guatemala, el transporte atraviesa los departamentos orientales, Izabal, Zacapa y Chiquimula, y luego a través del altiplano del departamento de Alta Verapaz y Petén hacia arriba, hasta México. Según datos oficiales, en 2010, 330 toneladas de cocaína por valor de 4 millones de dólares salieron de Guatemala. Las vías seguidas por los contrabandistas también corren a través de Nicaragua, Panamá y Costa Rica (UNODC 2012: 34-40). ${ }^{1}$

La Organización de las Naciones Unidas señala en sus informes que la corrupción de los funcionarios públicos en relación con el transporte ilegal de sustancias psicoactivas a través de las fronteras ha abierto el espacio para otros tipos de delitos de grupos organizados, como son el tráfico y la trata de personas, el contrabando de recursos naturales y, sobre todo, el comercio ilegal de armas y municiones, cuya demanda crece constantemente. Las distintas formas de delincuencia organizada suelen ir acompañadas del flujo de armas y de su uso. Las organizaciones criminales necesitan más armas para proteger los envíos, para asegurar las rutas del tráfico de personas, así como para luchar contra la influencia de otros grupos delictivos y las fuerzas del Estado. La demanda creciente de armas y de municiones también se ha visto favorecida por el desarrollo dinámico de los grupos criminales transnacionales, las maras y las bandas locales, las pandillas.

\footnotetext{
1 Después del 2006, en todos los países de la región, aumentaron los intentos de traficar con drogas. Los servicios de aduanas en los países latinoamericanos requisaron trece veces más cocaína que en México. El número de correos hacia México disminuyó de 174 en 2000 a 30 en 2011, mientras que a Panamá, Costa Rica, Honduras y Guatemala aumentó enormemente, sobre todo después del 2006. En Honduras, los incidentes ascendieron de 20 en el 2000 a 2333 en el 2011 (UNODC 2012: 32).
} 
La debilidad institucional y la crisis de la seguridad

En segundo lugar, debemos señalar la debilidad de las instituciones de seguridad y justicia en todos los países de América Central. Habría que buscar los orígenes de la crisis de la policía y del sistema judicial (tribunales, fiscalías) en los torpes y de hecho inacabados procesos de democratización de estos países, tras el período de dictaduras militares y guerras civiles, así como en su mala situación económica, lo cual tiene un impacto directo sobre la falta de financiación permanente de las instituciones públicas, incluidas las remuneraciones para los responsables de garantizar la seguridad y mantenimiento del orden público.

Las autoridades no han conseguido acabar, ni tan siquiera limitar, la patología de la corrupción que facilita el desarrollo del mercado negro de armas. Los funcionarios, mal remunerados, aprovechan la posibilidad de obtener ingresos adicionales y, a cambio de sobornos, se zafan de sus funciones, incluidas las relacionadas con la lucha contra el contrabando. En lugar de combatir las conexiones mafiosas, apoyan a los grupos criminales, protegiendo a los contrabandistas y los envíos ilegales de armas, proporcionando información sobre las pesquisas en curso y las redadas planeadas, y también muy a menudo legitimando el contrabando mediante la entrega de documentos pertinentes, e incluso vendiéndolos. De la involucración de los policías en actos delictivos son testimonio los numerosos veredictos judiciales, que condenan a oficiales por su participación en secuestros, tráfico de drogas y armas.

Unas instituciones policiales pobres y un poder judicial privado de la confianza ciudadana no son capaces de imponer y hacer cumplir efectivamente las disposiciones legales. La impunidad generalizada que prevalece en los países centroamericanos es un incentivo para las organizaciones criminales. Parece que ahora, en América Central, el problema no es sólo que las autoridades carecen de ideas para la lucha contra el crimen organizado, sino también, y quizá sobre todo, que las organizaciones criminales, gracias a los políticos, funcionarios y fuerzas de seguridad corruptos, se han hecho con la posibilidad de influir sobre la forma final de las estrategias de seguridad nacional, e incluso de reducir la capacidad de toma de decisiones y de paralizar el trabajo de las instituciones más importantes del Estado. Los agentes corruptos han dejado de llevar a cabo sus funciones de supervisión en cuanto al acceso a las armas y a la lucha contra el crimen organizado y el contrabando y se han enfocado más bien en la creación de un paraguas protector sobre las organizaciones criminales.

$\mathrm{Al}$ analizar los problemas institucionales de los países centroamericanos, es imposible ignorar el problema de la falta de control efectivo del tráfico fronterizo. Es tarea ardua controlar las fronteras en Centroamérica, debido a la gran extensión del área, al número de países que abarca (en un área de 500 mil. $\mathrm{km}^{2}$ hay siete países vecinos entre sí) y a la longitud de las fronteras terrestres y marítimas (solo las fronteras terrestres cuentan con $4 \mathrm{mil} \mathrm{km}$.). Existen dificultades adicionales asociadas a la aparición de pasos fronterizos, tanto legales
Armas de fuego e (in)seguridad en América Central en el siglo $X X I$

Michał Stelmach 
como ilegales, en las áreas protegidas (reservas naturales, comunidades autónomas de indígenas) y de duro acceso, a causa de la humedad del terreno y de la densa forestación (vastas zonas selváticas). Además, es necesario tener en cuenta que en las zonas fronterizas se hallan 185 municipios (la frontera con más municipios fronterizos es la de Honduras), donde viven aproximadamente el 13,1\% de los habitantes de la región (RCCPSH 2006: 34).

Vale la pena destacar que las fuerzas del Estado en las áreas fronterizas, especialmente en la costa, en principio están ausentes y no están representadas en realidad por ninguna institución. En estas zonas, habitadas sobre todo por pueblos indígenas, los principales y, a menudo, los únicos representantes del Estado son pequeños destacamentos de tropas. Sería una redundancia afirmar que la falta de supervisión por parte de las instituciones estatales ayuda, sin duda, al desarrollo de los grupos organizados criminales, lo que a su vez se convierte en clave para la proliferación del contrabando. Las autoridades centroamericanas son conscientes de sus propias debilidades y asimismo son conscientes de que las fronteras entre los vecinos tienen filtraciones. Según los acuerdos internacionales, en Centroamérica, las fronteras entre los Estados se pueden cruzar por 16 pasos fronterizos, en tanto que los funcionarios de la guardia fronteriza han detectado 96 lugares, a través de los cuales la frontera es cruzada sistemáticamente por miles de personas sin control alguno. Los servicios del Estado, debido a sus escasos recursos financieros, la falta de equipos, la escasez de personal, la corrupción generalizada y la ausencia de una estrategia regional para combatir el problema, ven muy limitadas sus posibilidades de acción, de modo que, en la práctica, poco pueden hacer para luchar eficazmente contra el tráfico. De hecho, los oficiales, aunque conocen los puntos donde se realizan las transferencias y poseen el conocimiento suficiente para detener a los delincuentes, contemplan pasivamente el flujo ilegal de armas, narcóticos y seres humanos.

Discrepancias en la legislación nacional con respecto al acceso a armas de fuego

El tráfico ilegal de armas en América Central es facilitado por una legislación incoherente en lo que respecta al acceso a armas de fuego. La falta de regulaciones legales consistentes favorece la compra de armas por parte de segundas personas llamadas "columnas" y conduce a una situación en la que las armas compradas legalmente en un país pueden importarse ilegalmente a un país vecino y colocarse allí en el mercado. Por otro lado, las soluciones legales adoptadas no permiten un control efectivo sobre el acceso y el comercio de armas.

En todos los países de la región, los ciudadanos tienen acceso a las armas (en Guatemala constitucionalmente). Los ciudadanos están obligados a solicitar una licencia para comprar y llevar un arma. En El Salvador, uno puede comprar dos armas al año, en Guatemala y Costa Rica, tres, pero en Guatemala 
esta restricción no se aplica a las agencias de seguridad privadas; en Honduras, cinco armas; en Panamá, hasta nueve armas; en Nicaragua, número ilimitado. Los permisos son temporales: dos años en Costa Rica y El Salvador, tres años en Panamá, con el consentimiento de los oficiales de policía y las fuerzas de seguridad y los agentes de seguridad; cuatro años en Honduras, cinco años en Nicaragua. En todos estos países, la ley prevé sanciones adecuadas para el tráfico ilegal de armas y tenencia de armas sin permiso o el uso indebido de ella: penas de prisión, multas (excepto Costa Rica) y la confiscación de las armas. Las divergencias aparecen en temas como el porte de armas en lugares públicos y los tipos de armas de que los civiles puedan disponer. A pesar de las regulaciones legales existentes falta un sistema eficiente de supervisión y control sobre las armas en poder de personas y entidades autorizadas a poseerlas (especialmente sobre las agencias de seguridad privadas). Las autoridades competentes, principalmente la policía, no cumplen con sus responsabilidades básicas debido a la escasez financiera y de personal.

\section{Conclusiones}

En resumen, la violencia criminal es un fenómeno común en Centroamérica, aunque está diversificada en términos de escala, intensidad y área de ocurrencia (principalmente en áreas urbanas). Su principal fuente son los grupos del crimen organizado, que incluyen maras y carteles de narcóticos, pero también, lo que es particularmente alarmante, las instituciones estatales que, luchando contra el crimen, recurren a métodos extremadamente represivos (la política de mano dura). Se llama la atención sobre el alto porcentaje de homicidios cometidos con el uso de armas de fuego en comparación con otros países latinoamericanos (con la excepción de Brasil). Parece que el mayor problema es un mercado negro extremadamente extenso, que garantiza a los ciudadanos -tanto delincuentes, como también residentes comunes de ciudades que quieren defenderse de los delincuentes- un fácil acceso a las armas. La principal fuente de armas, como se muestra en el artículo, son las agencias de seguridad privadas y los depósitos policiales, seguidos de los residuos después de la guerra civil, las colecciones privadas y las armas hechizas. Las transferencias internacionales ilegales de armas también desempeñan un papel importante. Vale la pena señalar que los Estados centroamericanos están en triple papel como fuente de armas para los grupos delictivos organizados que operan en México y Colombia, receptores de armas principalmente de los Estados Unidos, y un canal de transferencia para las armas que fluyen de los Estados Unidos a Colombia.

Analizando la violencia criminal en países de América Central, es fácil concluir que la disponibilidad de armas es solo uno de los factores que determinan el alto nivel de homicidios. En el artículo, señalé los determinantes más importantes, en mi opinión, del rápido desarrollo del comercio ilegal de armas y los altos niveles de violencia en la región, indicando principalmente 
el desarrollo dinámico del crimen organizado en los últimos años, la crisis institucional en el sector de seguridad pública y las discrepancias en las regulaciones nacionales sobre acceso a las armas de fuego. El que el uso de armas en la ejecución de asesinatos sea más frecuente en América Central que en otras regiones de América Latina, se debe también a la tradición sociopolítica y al gran arraigo de la violencia cotidiana.

Para reducir la violencia criminal en los Estados centroamericanos, los gobiernos deben tomar una serie de acciones concretas. En primer lugar, los gobiernos deben centrarse en la modernización de las instituciones responsables de la seguridad, es decir, la policía y los funcionarios de fronteras, y del poder judicial, los tribunales y la oficina del fiscal, porque sólo la firmeza para imponer y hacer cumplir la ley puede terminar con este período de impunidad generalizada, que ha venido a fomentar el desarrollo de diversos tipos de delitos de carácter organizado y conectados con el comercio ilegal de armas de las instituciones y con el bandidaje común. Solo una mejora decisiva para mantener el orden público reducirá la tendencia de los ciudadanos centroamericanos de poseer armas, a fin de garantizar su seguridad personal. A su vez, atajar el problema del fácil acceso a las armas por parte de los grupos delictivos parece ser un requisito primordial para su desmantelamiento definitivo, que se traducirá en una disminución real en el nivel de violencia. En segundo lugar, los Estados deben tratar de uniformar las leyes relativas a la tenencia y porte de armas, así como a todas las normas relacionadas con la cadena en el suministro de armas de tiro y de mano. La armonización de las leyes y el fortalecimiento del sistema de control permitirá evitar situaciones en las que los Estados débiles se utilizan como puntos de aterrizaje y despegue $y$, con una frecuencia cada vez mayor, también como centros o bases de diversos grupos criminales.

\section{Referencias bibliográficas}

Arias P., Rosada Granados H. (2012), Reformas policiales en América Latina: principios, lineamientos progresistas, Friedrich-Ebert-Stiftung, Programa de Cooperación en Seguridad Regional, Bogotá.

Arias P. (2009), Seguridad Privada en América Latina: el lucro y los dilemas de una regulación deficitaria, FLACSO, Santiago de Chile, disponible en: https://issuu.com/flacso.chile/docs/ rss6_2009

Arias O. (2008), El proceso plurinacional sobre el control de transferencias y del tráfico de armas en América Central, Fundación Arias para la Paz y Proceso Humano.

Bosworth J., Kinosian S. (2018), Security for sale. Challenges and Good Practices in Regulating Private Military and Security Companies in Latin America, Rule of Law Program Report, The Dialogue.

Costa G. (2012), La situación de la seguridad ciudadana en América Latina, "Inter-American Dialogue", Febrero 2012. 
Clavel T. (2018), Balance de InSight Crime sobre homicidios en Latinoamérica en 2017, InSight Crime Report, disponible en: https://es.insightcrime.org/noticias/analisis/balancede-insight-crime-sobre-homicidios-en-latinoamerica-en-2017/.

Dalby C., Carranza C. (2019), Balance de InSight Crime sobre los homicidios en 2018, InSight Crime, disponible en: https://es.insightcrime.org/noticias/analisis/balance-de-insight-crimesobre-los-homicidios-en-2018/

Dammert L. (2014), Dos décadas de reformas policiales en América Latina. Lecciones y desafios, en: Violencia, delincuencia y seguridad publica en América Latina, R. Codova Macias, G. Maihold, Grupo Editorial Cenzontle, México.

Espinoza Y. A., Orozco L. (2018), El proceso plurinacional sobre el control de transferencias $y$ del tráfico de armas en América Central, Fundación Arias para la Paz y el Progreso Humano, San José.

Gilgen E. (2012), A Fatal Relationship. Guns and Deaths in Latin America and the Caribbean, Small Arms Survey.

Godnick W. (2016), Armed Private Security in Latin America: oversight and accountability in an evolving context. Regional study, UNLIREC, DCAF.

Godnick W., Bustamante J. (2013), El tráfico de armas de fuego en América Latina y el Caribe: mitos, realidades y vacíos en la agenda internacional de investigación, en: Seguridad regional en América Latina y el Caribe. Anuario 2013, C. Guarnizo (ed.), Friedrich Ebert Stiftung, Bogotá.

Godnick W., Vazquez H. (2003), Control de armas pequeñas en Centroamérica, Proyecto para la implementación de Controles de Armas Pequeñas (MISAC), no 2.

Karczewski M. (2011), System kontroli i regulacji międzynarodowego handlu uzbrojeniem, „Przegląd Strategiczny”, nr 2.

Rosa de León-Escribano C. (2011), Tráfico ilícito de armas y municiones: Guatemala y región centroamericana, "Urvio, Revista Latinoamericana de Seguridad Ciudadana”, no 10, noviembre, Quito.

Ley de Armas y Municiones No 7957.

Ley de Control de Armas de Fuego, Municiones, Explosivos y Artículos Similares, Decreto Legislativo No 655.

Liberska B. (2008), Ameryka Łacińska - w poszukiwaniu nowej strategii rozwoju i modelu globalizacji, en: Doświadczenie demokracji w Ameryce Łacińskiej, M. Kania, A. KaganiecKamieńska (eds.), Wydawnictwo UJ, Kraków.

Lucatello S. (2012), El desafío de tráfico de armas en México y Centroamérica, en: Atlas de la Seguridad y defensa de México 2012, S. Aguayo Quezada, R. Manaut (eds.), CASEDE, México.

Oficina de las Naciones Unidas contra la Droga y el Delito (2012), Armas de fuego en Centroamérica, en: Delincuencia organizada transnacional en Centroamérica y el Caribe: una evaluación de las amenazas, UNODC, Viena.

REDCEPAZ (2006), El problema de las armas ilegales en Centroamérica: un acercamiento al problema, proyecto abordando el problema del tráfico ilícito de armas desde una perspectiva regional, Red Centroamericana para la Construcción de la Paz y Seguridad Humana (REDCEPAZ), Guatemala.

Reglamento a la Ley de Armas y Explosivos N 25120-SP.
Armas de fuego e (in)seguridad en América Central en el siglo XXI

Michał Stelmach 
Saavedra B. (2007), Transnational Crime and Small Arms Trafficking and Proliferation, en: Transnational Threats: Smuggling and Trafficking in Arms, Drugs, and Human Life, K. Thachuk (red.), CT: Praeger Security International, Westport.

Santamaria G. (2013), La difusión y contención del crimen organizado en la subregión MéxicoCentroamérica, en: La diáspora criminal: la difusión transnacional del crimen organizado y como contener su expansión, J. Garzón, E. Olson (ed.), Woodrow Wilson Center Reports on the Americas, no 31, Washington.

Stohl R. (2006), The Small Arms Trade in Latin America.

Stohl R. and Tuttle D. (2008), The Small Arms Trade in Latin America, NACLA Report on the Americas, vol. 41, no 2, March/April.

UNODC (2012), Armas de fuego en Centroamérica, en: Delincuencia organizada transnacional en Centroamérica y el Caribe: una evaluación de amenazas, Oficina de las Naciones Unidas contra la Droga y el Delito, Viena.

UNODC (2012), La importancia de los grupos territoriales en Centroamérica, en: Delincuencia organizada transnacional en Centroamérica y el Caribe: una evaluación de las amenazas, Oficina de las Naciones Unidas contra la Droga y el Delito, Viena. 